\title{
Effect of waiting time for placing resin composite restorations after bleaching on enamel bond strength
}

\author{
Alice Hammes Pimentel ${ }^{1}$, Lisia Lorea Valente ${ }^{2}$, Cristina Pereira Isolan², Eliseu Aldrighi Münchow², \\ Evandro Piva ${ }^{1,2}$ and Rafael Ratto de Moraes ${ }^{1,2^{*}}$
}

${ }^{*}$ Correspondence:

moraesrr@gmail.com

${ }^{2}$ Graduate Program

in Dentistry, Federal

University of Pelotas, Pelotas, RS, Brazil

Full list of author information is available at the end of the article

\begin{abstract}
This study investigated the influence of the waiting time for placing resin composite (RC) restorations after dental bleaching on the shear bond strength (SBS) to enamel. Seventy bovine incisors were obtained, of which 60 were stained in coffee solution for 1 week and then bleached with the whitening agent Lase Peroxide Sensy (DMC Equipments, Brazil), following the manufacturer directions of use. Next, all teeth were allocated into seven groups $(n=10)$ according to the waiting time after bleaching for placing the RC: immediately ( $0 \mathrm{~h}$ ), $24 \mathrm{~h}, 3,7,14$ and 28 days (d). Ten teeth were not bleached to serve as control. The specimens were prepared for SBS test and also for failure mode analysis. Scanning electron microscopy images were taken in nonbleached and bleached specimens. Data was analyzed by one-way ANOVA and Tukey's test $(a=0.05)$. The SBS means (standard deviations), in $\mathrm{MPa}$, were: control $=8.5^{\mathrm{b}}(5.8)$; $0 \mathrm{~h}=14.5^{\mathrm{a}}(5.9) ; 24 \mathrm{~h}=18.8^{\mathrm{a}}(7.4) ; 3 \mathrm{~d}=15.7^{\mathrm{a}}(0.1) ; 7 \mathrm{~d}=15.6^{\mathrm{a}}(7.0) ; 14 \mathrm{~d}=15.0^{\mathrm{a}}$ (6.7); and $28 \mathrm{~d}=17.9^{\mathrm{a}}$ (7.7). All bleached groups resulted in similar SBS to enamel ( $p \geq 0.221)$, but higher than the control $(p \leq 0.004)$. Adhesive failures were predominant in all groups. Bleaching produced an acid-etching pattern (enamel prisms exposure) on enamel, differently to the non-bleached teeth, which showed an unaltered surface. In conclusion, dental bleaching did not affect resin-enamel bond strength, regardless of the waiting time to place the restoration after bleaching.
\end{abstract}

Keywords: Tooth bleaching, Dental enamel, Shear strength, Microscopy

\section{Background}

Esthetic restorative treatments in dentistry commonly involve dental bleaching before use of direct or indirect restorative materials. Bleaching is performed in an attempt to return the white appearance and natural color shade of stained teeth, whereas the restoration corrects the anatomical shape and function of teeth, as well as the harmony of a defective smile [1].

Tooth bleaching is an oxidative process of high-molecular weight molecules adhered to enamel and dentin. This process is characterized by two main steps: first, peroxide molecules found in whitening agents diffuse into the tooth producing free radicals, reactive oxygen molecules, and hydrogen peroxide anions [2]. Next, all these molecules initiate the oxidation process, breaking the pigments down into smaller parts [3]. After

(c) 2015 Pimentel et al. This article is distributed under the terms of the Creative Commons Attribution 4.0 International License (http://creativecommons.org/licenses/by/4.0/), which permits unrestricted use, distribution, and reproduction in any medium, provided you give appropriate credit to the original author(s) and the source, provide a link to the Creative Commons license, and indicate if changes were made. 
this process, the release of oxygen species from the teeth is not immediate, which may remain arrested for several days [4]. Consequently, polymerization of resin-based materials (e.g., dental adhesives, resin composites, and resin cements) may be compromised since oxygen is a well-known inhibitor of polymerization reactions [5], thus affecting negatively the bond strength between resin materials and the tooth. Taking this into account, the literature advices that it would be prudent to wait for a period of time between the end of bleaching treatment and placement of adhesive restorations, unless if antioxidant substances are applied on the tooth in an attempt to completely remove the remaining oxygen molecules [4, 6-9].

Several studies have demonstrated that the bond strength between restorative materials and teeth is improved when a period of time after bleaching is waited to proceed with placement of the restoration [10-15], although they diverge regarding to the minimum waiting time necessary for that effect to take place. By contrast, other studies have found no significant difference in bond strength results between specimens restored immediately after bleaching or after waiting an interval period [13, 16, 17]. Hence, the purpose of the present study was to investigate whether the waiting time between placement of a resin composite restoration and the end of the bleaching procedure has an influence on the enamel bond strength. The hypothesis tested was that longer waiting times for placing the composite restoration would be associated with higher bond strength to enamel.

\section{Methods}

\section{Preparation of specimens and groups tested}

Seventy bovine incisors were obtained, cleaned, and stored in $0.5 \%$ chloramine-T aqueous solution for 1 week. The roots were cut off and each crown was wet ground using 600-grit $\mathrm{SiC}$ abrasive papers in order to standardize the enamel surface. Sixty specimens were then stained in coffee solution for 7 days, as previously described [18]. Next, these 60 specimens were randomly allocated into six groups, according to the waiting time for placing the resin composite restoration after bleaching treatment: immediately $(0 \mathrm{~h})$, $24 \mathrm{~h}, 3,7,14$, and 28 days (d). The ten non-bleached specimens were used in the negative control group.

\section{Bleaching and restorative procedures}

The teeth were bleached using 35 \% hydrogen peroxide gel (Lase Peroxide Sensy, DMC Equipments, São Carlos, SP, Brazil), whose manufacturer's information, lot number, and directions of application are described in Table 1. After bleaching, the specimens were restored with resin composite (Filtek Z350, 3 M ESPE, St. Paul, MN, USA). Before placing the composite, the specimens were acid-etched with $37 \%$ phosphoric acid for $30 \mathrm{~s}$, rinsed with distilled water for $30 \mathrm{~s}$, dried with compressed air for $15 \mathrm{~s}$, coated with two layers of Single Bond 2 (3 M ESPE), dried again with compressed air for $5 \mathrm{~s}$, and covered with a silicone mold containing four orifices ( $1.5 \mathrm{~mm}$ in diameter, $0.5 \mathrm{~mm}$ in thickness). The specimens were light-activated with a light-emitting diode curing unit (Radii, SDI, Bayswater, VIC, Australia, $1200 \mathrm{~mW} / \mathrm{cm}^{2}$ irradiance) for $20 \mathrm{~s}$ in each orifice, and the composite was used to fill the orifices, followed by light-activation for $20 \mathrm{~s}$. Next, specimens were stored for $24 \mathrm{~h}$ in distilled water, at $37^{\circ} \mathrm{C}$. 
Table 1 Manufacturer information, lot number, and directions of application of the hydrogen peroxide agents used in the study

\begin{tabular}{|c|c|c|c|}
\hline Material & Manufacturer & Lot & Instructions of application \\
\hline Lase peroxide sensy & DMC equipments & 40113 & $\begin{array}{l}\text { Gel preparation: mix } 3 \text { drops of peroxide (phase 1) for every } \\
\text { drop of thickener (phase } 2 \text { ) with the aid of a spatula } \\
\text { Gel application: apply the gel from } 1 \mathrm{~mm} \text { to } 2 \mathrm{~mm} \text { of thickness } \\
\text { using a spatula or syringe } \\
\text { Gel irradiation: irradiate with Whitening Lase II for } 1 \mathrm{~min} \text {; let the } \\
\text { gel to rest for } 3 \text { min, repeating the irradiation and resting } \\
\text { procedures twice more } \\
\text { Gel removal: after } 10 \text { to } 15 \text { min of application, remove the gel } \\
\text { with the aspirator tip and clean the surface with gauze } \\
\text { Repeat the previous procedures up to two times more, depending } \\
\text { on the result obtained }\end{array}$ \\
\hline
\end{tabular}

\section{Shear bond strength (SBS) test and fracture mode analysis}

The SBS of each specimen was tested as previously described [19]. Briefly, a thin metal wire was looped around each composite cylinder and subjected to a shear load using a mechanical testing machine (DL500; EMIC, São José dos Pinhais, PR, Brazil) at a crosshead speed of $1 \mathrm{~mm} / \mathrm{min}$ until failure. SBS data were expressed in MPa. Data were submitted to a One-Way Analysis of Variance and Tukey's test $(\alpha=0.05)$ using SigmaPlot v.12 software (Systat Software Inc., San Jose, CA, USA). For fracture mode analysis, each specimen was observed at $20 \times$ magnification under a light stereomicroscope, and the failure modes were categorized as adhesive (failure at the composite-enamel interface), cohesive in enamel, or mixed failure.

\section{Scanning electron microscopy (SEM) evaluation}

Two specimens were also prepared and wet-ground using 320, 600, and 1500-grit SiC papers, followed by polishing with felt disc for $5 \mathrm{~min}$, cleansing in ultrasonic water bath, and drying with compressed air for $30 \mathrm{~s}$. The specimens were separated into two groups: one that remained non-bleached and one that was bleached as described before. After dehydration in ascending ethanol concentrations (70, 80, 90, and $100 \%)$ for 15 min each, the specimens were dried for $15 \mathrm{~s}$ with compressed air and kept in contact with a filter paper at room temperature. After $24 \mathrm{~h}$, the specimens were mounted on aluminum stubs and sputter-coated with gold/palladium alloy for SEM evaluation (SSX-550; Shimadzu, Tokyo, Japan). The enamel surface morphology was evaluated qualitatively.

\section{Results and discussion}

According to results displayed in Fig. 1, all bleached groups had similar SBS regardless of the waiting time before placement of the restoration ( $p \geq 0.221$ ). Therefore, the hypothesis tested was rejected. One of the main aspects that may explain this finding is the absence of residual oxygen molecules at the enamel surface/structure, thus allowing a proper polymerization of the adhesive and the resin composite used. According to previous studies, oxygen may not necessarily accumulate within the near enamel surface [20, 21], whereas dentin may act as a true reservoir of oxygen molecules [22]. This suggests that the different waiting time intervals investigated in the present study did not modify the enamel, explaining the similar results obtained. 


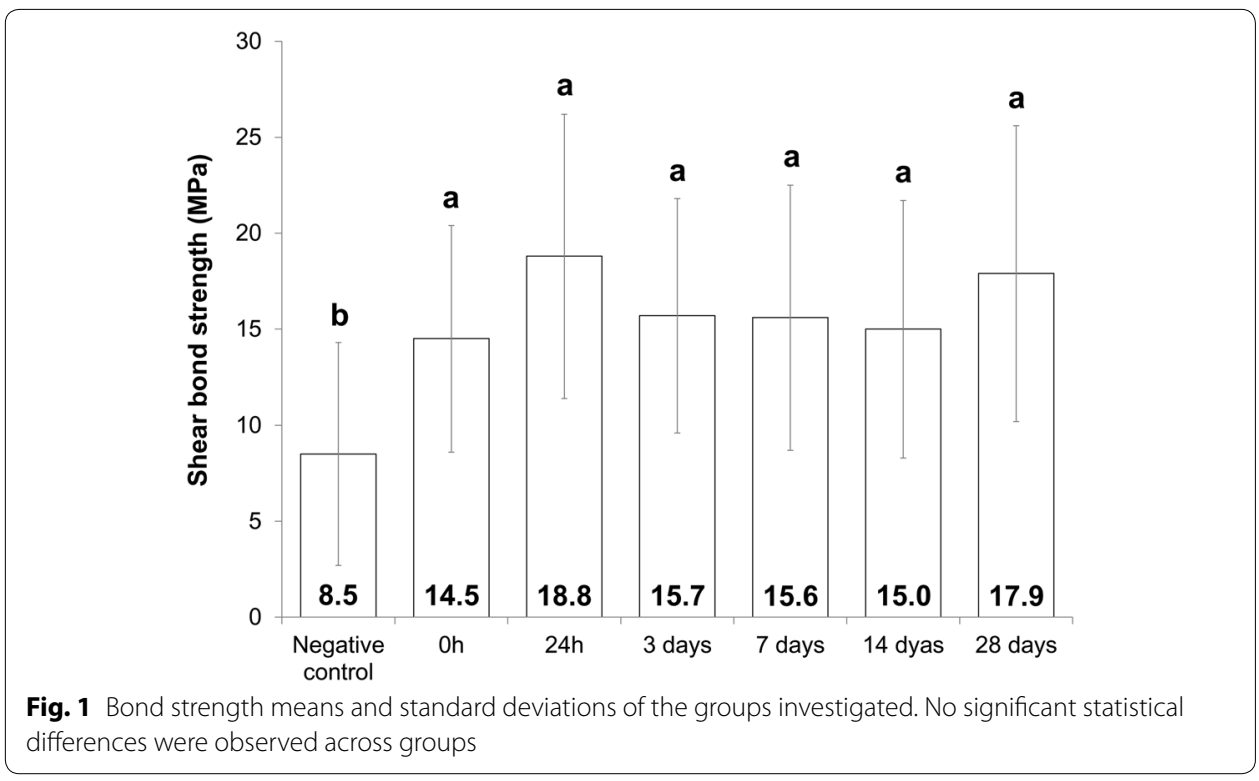

The research question of this study is still questionable in the literature, since while some studies demonstrate that adhesive procedures should not be performed immediately or even after a few days or weeks after bleaching [10-15, 23], other studies state that there is no need to wait a specific time interval to proceed with the restorative treatment $[13,16,17]$. These divergent results may perhaps be material-dependent, that is, the bonding process to bleached teeth depends on the type of whitening agent used [13, 24], as well as on the type of adhesive systems and/or restorative materials applied [25]. Regarding to the "whitening agent" factor, materials may vary according to their hydrogen peroxide concentration, time of application, and $\mathrm{pH}$ of the gel; considering that only $\mathrm{pH}$ would more importantly influence SBS, the present study also evaluated the morphology of enamel after bleaching. According to the SEM imagens shown in Fig. 2, the gel exposed the prism rods of enamel in a similar way that phosphoric acid does. Moreover, a clear rougher surface could be observed when compared to the non-bleached specimen.

Considering that the enamel bond strength is a process still dependent on the micromechanical interlocking between the resin monomers and substrate [26, 27], it can be suggested that a satisfactory resin-enamel interaction was obtained in all bleached specimens, resulting in the similar SBS results observed here. By contrast, the non-bleached specimens (negative control group) had significantly lower SBS than all bleached groups, probably because the staining molecules adhered to enamel and were not bleached out from the surface, interfering with proper action of phosphoric acid for optimal adhesion. Moreover, although the most frequent fracture mode was adhesive (i.e., at the interface), mixed and cohesive failures were detected only in bleached teeth (Fig. 3), which corroborates the SBS results indicating better mechanical keying to bleached compared to non-bleached enamel surfaces.

Interestingly, some recent studies have demonstrated that bleaching agents containing varied content of hydrogen peroxide may be successfully used for increasing the 

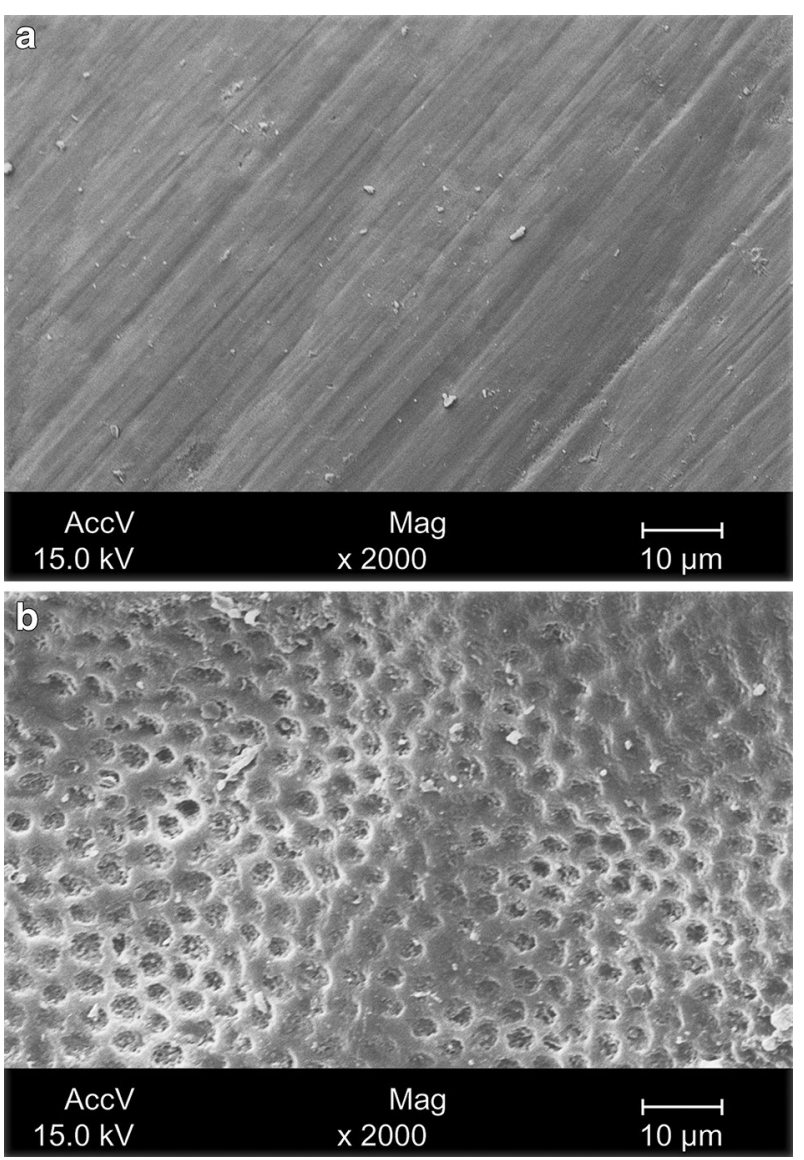

Fig. 2 SEM micrographs of non-bleached (a) and bleached (b) enamel surfaces

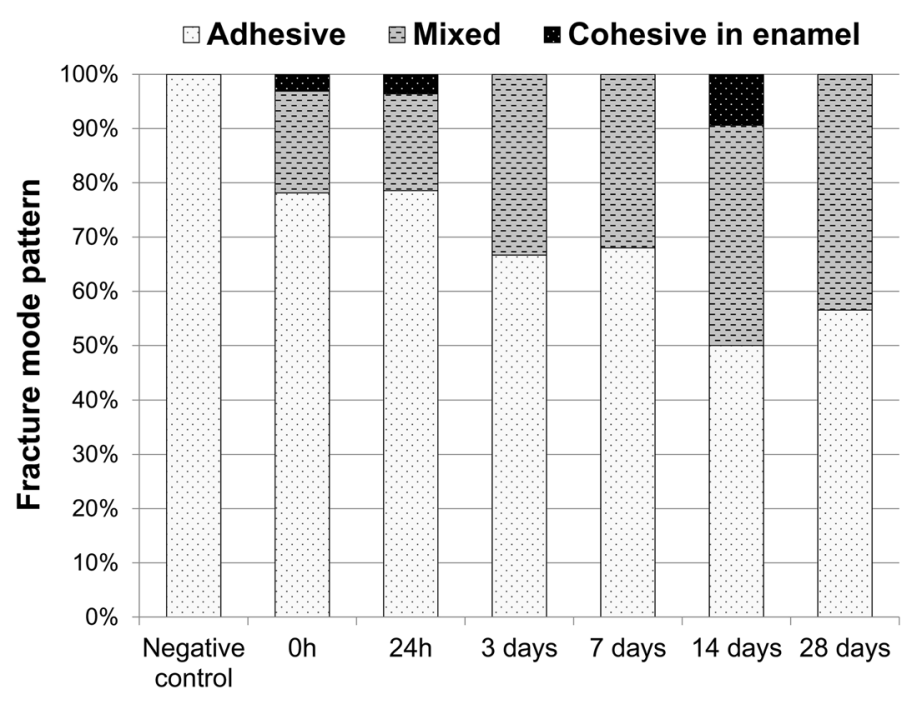

Fig. 3 Distribution of failure modes between groups 
bonding ability of glass fiber-reinforced posts to the root canal since they are able to etch the post surface [28-30]. Furthermore, whitening agents vary in $\mathrm{pH}$, and gels with a more acidic nature would etch the tooth surface in a similar way that phosphoric acid or self-etch adhesives do, as demonstrated by the present study (particularly the SEM images).

\section{Conclusion}

The bond strength between resin composite and enamel does not seem to be influenced by in-office bleaching using $35 \%$ hydrogen peroxide, suggesting that clinicians may restore teeth immediately after bleaching is completed.

Authors' contributions

LLV and CPI participated in the supervision of the experiments and in the writing of the manuscript. AHP participated in performing the experiments. EAM participated in the design of the study and performed the statistical analysis. EV and RRM supervised the laboratory work, participated in its design and coordination, and drafted the manuscript. All authors read and approved the final manuscript.

Author details

${ }^{1}$ School of Dentistry, Federal University of Pelotas, Rua Gonçalves Chaves, 457, Postal 96015-560 Pelotas, RS, Brazil.

${ }^{2}$ Graduate Program in Dentistry, Federal University of Pelotas, Pelotas, RS, Brazil.

\section{Competing interests}

The authors declare that they have no competing interests.

Received: 16 November 2015 Accepted: 9 December 2015

Published online: 18 December 2015

\section{References}

1. Ittipuriphat I, Leevailoj C. Anterior space management: interdisciplinary concepts. J Esthet Restor Dent. 2013;25:16-30.

2. Dahl JE, Becher R. Acute toxicity of carbamide peroxide and a commercially available tooth-bleaching agent in rats. J Dent Res. 1995;74:710-4.

3. Thickett E, Cobourne MT. New developments in tooth whitening. The current status of external bleaching in orthodontics. J Orthodontics. 2009;36:194-201.

4. Swift EJ Jr. Critical appraisal. Reversal of compromised bonding after bleaching. J Esthet Restor Dent. 2012;24:357-61.

5. Gauthier MA, Stangel I, Ellis TH, Zhu XX. Oxygen inhibition in dental resins. J Dent Res. 2005;84:725-9.

6. Freire A, Durski MT, Ingberman M, Nakao LS, Souza EM, Vieira S. Assessing the use of 35 percent sodium ascorbate for removal of residual hydrogen peroxide after in-office tooth bleaching. J Am Dent Assoc. 2011;142:836-41.

7. Kimyai S, Valizadeh $\mathrm{H}$. The effect of hydrogel and solution of sodium ascorbate on bond strength in bleached enamel. Oper Dent. 2006;31:496.

8. Turkun M, Celik EU, Kaya AD, Arici M. Can the hydrogel form of sodium ascorbate be used to reverse compromised bond strength after bleaching? J Adhesiv Dent. 2009;11:35-40.

9. Berger SB, De Souza Carreira RP, Guiraldo RD, Lopes MB, Pavan S, Giannini M, Bedran-Russo AK. Can green tea be used to reverse compromised bond strength after bleaching? Eur J Oral Sci. 2013;121:377-81.

10. Hussain M, Wang Y. Influence of prolonged light-curing time on the shear bonding strength of resin to bleached enamel. Oper Dent. 2010;35:672-81.

11. Lago AD, Garone-Netto N. Microtensile bond strength of enamel after bleaching. Indian J Dent Res. 2013;24:104-9.

12. doRego MV, dosSantos RM, Leal LM, Braga CG. Evaluation of the influence of dental bleaching with $35 \%$ hydrogen peroxide in orthodontic bracket shear bond strength. Dental Press J Orthod. 2013;18:95-100.

13. Spyrides GM, Perdigao J, Pagani C, Araujo MA, Spyrides SM. Effect of whitening agents on dentin bonding. J Esthet Restor Dent. 2000;12:264-70.

14. Can-Karabulut DC, Karabulut B. Influence of activated bleaching on various adhesive restorative systems. J Esthet Restor Dent. 2011;23:399-408.

15. Nascimento GC, de Miranda CA, Machado SM, Brandao GA, de Almeida HA, Silva CM. Does the time interval after bleaching influence the adhesion of orthodontic brackets? Korean J Orthod. 2013;43:242-7.

16. Immerz I, Proff P, Roemer P, Reicheneder C, Faltermeier A. An investigation about the influence of bleaching on shear bond strength of orthodontic brackets and on enamel colour. Int Scholar Res Notices Dent. 2012;2012:375849.

17. Gurgan S, Alpaslan T, Kiremitci A, Cakir FY, Yazici E, Gorucu J. Effect of different adhesive systems and laser treatment on the shear bond strength of bleached enamel. J Dent. 2009;37:527-34.

18. Meireles SS, Fontes ST, Coimbra LA, Della Bona A, Demarco FF. Effectiveness of different carbamide peroxide concentrations used for tooth bleaching: an in vitro study. J Appl Oral Sci. 2012;20:186-91. 
19. Münchow EA, Bossardi M, Priebe TC, Valente LL, Zanchi CH, Ogliari FA, Piva E. Microtensile versus microshear bond strength between dental adhesives and the dentin substrate. Int J Adhes Adhes. 2013;46:95-9.

20. Ruse ND, Smith DC, Torneck CD, Titley KC. Preliminary surface analysis of etched, bleached, and normal bovine enamel. J Dent Res. 1990;69:1610-3.

21. Perdigao J, Francci C, Swift EJ Jr, Ambrose WW, Lopes M. Ultra-morphological study of the interaction of dental adhesives with carbamide peroxide-bleached enamel. Am J Dent. 1998;11:291-301.

22. Titley KC, Torneck CD, Ruse ND, Krmec D. Adhesion of a resin composite to bleached and unbleached human enamel. J Endod. 1993;19:112-5.

23. Didier VF, Batista AUD, Montenegro RV, Fonseca RB, Carvalho FG, Barros S, Carlo HL. Influence of hydrogen peroxidebased agents on the bond strength of resin-enamel/dentin interfaces. Int J Adhes Adhes. 2013;47:141-5.

24. Dietrich AM, English J, McGrory K, Ontiveros J, Powers JM, Bussa HI Jr, Salas-Lopez A. A comparison of shear bond strengths on bleached and unbleached bovine enamel. Texas Dental J. 2010;127:285-91.

25. Dudek M, Roubickova A, Comba L, Housova D, Bradna P. Effect of postoperative peroxide bleaching on the stability of composite to enamel and dentin bonds. Oper Dent. 2013;38:394-407.

26. Pashley DH, Tay FR, Breschi L, Tjaderhane L, Carvalho RM, Carrilho M, Tezvergil-Mutluay A. State of the art etch-andrinse adhesives. Dent Mater. 2011;27:1-16.

27. Van Meerbeek B, Yoshihara K, Yoshida Y, Mine A, De Munck J, Van Landuyt KL. State of the art of self-etch adhesives. Dent Mater. 2011;27:17-28.

28. Braga NM, Souza-Gabriel AE, Messias DC, Rached-Junior FJ, Oliveira CF, Silva RG, Silva-Sousa YT. Flexural properties, morphology and bond strength of fiber-reinforced posts: influence of post pretreatment. Brazilian Dent J. 2012;23:679-85

29. de Sousa Menezes M, Queiroz EC, Soares PV, Faria-e-Silva AL, Soares CJ, Martins LR. Fiber post etching with hydrogen peroxide: effect of concentration and application time. J Endod. 2011;37:398-402.

30. Elsaka SE. Influence of chemical surface treatments on adhesion of fiber posts to composite resin core materials. Dent Mater. 2013;29:550-8.

\section{Submit your manuscript to a SpringerOpen ${ }^{\circ}$ journal and benefit from:}

- Convenient online submission

- Rigorous peer review

- Immediate publication on acceptance

- Open access: articles freely available online

- High visibility within the field

- Retaining the copyright to your article

Submit your next manuscript at $\mathbf{s p r i n g e r o p e n . c o m ~}$ 